\title{
Mental health consequences of the COVID-19 pandemic associated with social isolation
}

\section{Consecuencias de la pandemia de la COVID-19 en la salud mental asociadas al aislamiento social

\author{
Jairo Ramírez-Ortiz ${ }^{\mathrm{a}, \mathrm{b}}$ (D), Diego Castro-Quintero ${ }^{\mathrm{a}}$ (D) , Carmen Lerma-Córdoba ${ }^{\mathrm{D}}$, \\ Francisco Yela-Ceballos ${ }^{a}$ (D) Franklin Escobar-Córdoba ${ }^{a, b, c}$ (D)
}

\author{
${ }^{a}$ Psychiatry Department, School of Medicine, Universidad Nacional de Colombia. Bogotá, Colombia \\ ${ }^{\mathrm{b}}$ Hospital Universitario Nacional de Colombia. Bogotá, Colombia \\ c Fundación Sueño Vigilia Colombiana. Bogotá, Colombia.
}

Correspondence: Departamento de Psiquiatría. Facultad de Medicina. Universidad Nacional de Colombia. Oficina 202, Facultad de Medicina, Campus Universitario. Bogotá D. C., Colombia. Email: feescobarc@unal.edu.co

\section{What do we know about this issue?}

From studies about epidemics prior to COVID-19, it is known that about a third of the affected population needed care for mental health services, mainly due to anxiety disorders, post-traumatic stress disorder and depression.

\section{¿What is this study's contribution?}

This article presents studies that have been developed on alterations in mental health secondary to the COVID-19 pandemic. In addition, recommendations and guidelines for psychotherapeutic and pharmacological intervention are provided.

\section{How to cite this article:}

Ramírez-Ortiz], Castro-Quintero D, Lerma-Córdoba C, Yela-Ceballos F, Escobar-Córdoba F. Mental health consequences of the COVID-19 pandemic associated with social isolation. Colombian Journal of Anesthesiology. 2020;48(4):e930.

\section{Abstract}

The 2019 coronavirus pandemic (COVID-19) is a public health emergency of international concern, which poses a major challenge to mental health as a result of its unprecedented impact in this 21st century. Research in past epidemics has revealed a deep and wide range of psychosocial consequences at the individual and collective level. There are multiple associated psychological disturbances, ranging from isolated symptoms to complex disorders with marked impairment of functionality, such as insomnia, anxiety, depression, and post-traumatic stress disorder. Therefore, it is necessary for mental health services to develop strategies that allow them to react skillfully and provide support to health workers and the affected population so as to reduce the psychological impact as well as the development of psychiatric symptoms. The purpose of this reflection article is to show the possible consequences on the mental health of the population as a result of social isolation due to the COVID-19 pandemic.

\section{Keywords}

Pandemics; social isolation; coronavirus infections; anxiety disorders; depression; stress disorders; posttraumatic.

\section{Resumen}

La pandemia por coronavirus 2019 (COVID-19) es una emergencia de salud pública de preocupación internacional, con impactos sin precedentes en el siglo XXI y hoy representa un gran desafío a la salud mental. Estudios en epidemias anteriores han revelado una profunda y amplia gama de consecuencias psicosociales a nivel individual y comunitario durante los brotes. Son múltiples las alteraciones psicológicas asociadas, que van desde síntomas aislados hasta trastornos complejos, con un deterioro marcado de la funcionalidad, como insomnio, ansiedad, depresión y trastorno por estrés postraumático. En este contexto es necesario que las entidades de salud mental desarrollen estrategias que permitan reaccionar con destreza y que logren un soporte al personal de salud y a la población afectada, en aras de reducir el impacto psicológico y de los síntomas psiquiátricos. Este artículo de reflexión tiene por objetivo mostrar las posibles consecuencias en la salud mental de la población, como resultado del aislamiento social debido a la pandemia de la COVID-19.

\section{Palabras clave}

Pandemias; aislamiento social; infecciones por coronavirus; trastornos de ansiedad; depresión; trastornos por estrés postraumático. 


\section{INTRODUCTION}

The unavoidable focus on the issue of transmission and the physical repercussions of COVID-19 worldwide might well minimize public interest in the psychosocial consequences for the people affected by the virus (1). It is worth highlighting that the emerging mental health issues may evolve into health problems in the near future. During the epidemics of severe acute respiratory syndrome (SARS) and SARS-CoV in 2003, and the Middle-East respiratory syndrome in 2012 (in which the number of people affected by the infection was no where near that of the current pandemic), it was found that nearly $35 \%$ of those people who survived the first outbreak developed psychiatric symptoms during the early recovery phase $(2,3)$. In the case of MERS$\mathrm{CoV}$, close to $40 \%$ of the people affected required psychiatric intervention (4).

In normal circumstances, people in social isolation, with restricted mobility and little contact with other individuals, are prone to develop psychiatric complications ranging from isolated symptoms to overt mental disorders such as insomnia, anxiety, depression and post-traumatic stress disorder (PTSD) (5). In the context of a pandemic, it is important to take into consideration the loss of functionality associated with the acquired disease which may translate into a feeling of dejection and helplessness, leading even to a state of bereavement (5). On the other hand, people under the stress of the outbreak may exhibit marked anxiety and significant decline in social or occupational function, resulting in adaptation disorders and, in the event of sad mood persistence, in major depression disorder (MDD) (5). Moreover, proximity to events that threaten life and survival, as is the case of the disease itself, may trigger the development of PTSD, so much so, that it has been suggested that the combined effect of loss and threat may explain the frequent concomitant occurrence of PTSD and depression (6).

Although a large number of people are affected by the pandemic, vulnerable populations require special attention. These include, 1) patients and their families, 2) people with pre-existing physical and/ or mental medical conditions, and 3) healthcare workers, in particular nurses and physicians working directly with patients and quarantined populations (1). It is worth mentioning that patients with a history of mental disease deserve special attention (7), because treatment discontinuation due to challenges with follow-up, limited specialized care, poor dosing control and low availability of medications may unleash careless behaviors due to impaired judgement, leading to risky behaviors and difficulty following instructions and public regulations. This engenders the risk of infringement of the measures designed to keep the outbreak at bay $(5,8)$.

Another significantly affected group is that of healthcare workers. They have been found to exhibit mental disorders, in particular PTSD in up to $20 \%$ of cases (9), depressive disorder or adjustment responses with higher levels of anxiety after an outbreak. This is due mainly to social isolation and separation from their loved ones as a result of their duties at work; direct exposure to the disease and fear of acquiring the infection while on duty $(8,10)$; ethical dilemmas pertaining to the allocation of scarce resources to patients with the same needs, and having to provide care to severely ill patients with limited or inadequate resources (11). How to balance their own needs for physical and mental health with those of their patients? How can they align their wishes and duties towards their patients with those of their relatives and friends?(11). Having to witness how throngs of patients and healthcare workers die, working in highly stressful environments with a shortage of staff or replacements are risk factors for developing burnout syndrome (5). The objective of this article is to show the potential mental health consequences for the population as a result of mandatory social isolation due to the COVID-19 pandemic.

\section{BACKGROUND}

\section{Psychosocial impact of the SARS- CoV (2003) and MERS-CoV (2012) pandemics}

A population exposed to an epidemic may experience multiple psychosocial effects. For example, in the wake of the SARS$\mathrm{CoV}$ outbreak in Taiwan, a pessimistic view of life was evident in close to $10 \%$ of the population, together with an $11.7 \%$ prevalence of psychiatric morbidity during the ensuing months. (12) Around the same time, in Singapore, close to $27 \%$ of the healthcare workforce reported psychiatric symptoms after the epidemic (13). Likewise, PTSD was found in $20 \%$ of physicians and nurses, and the analysis showed that those who received support from their supervisors and peers were less prone to developing PTSD (9). Along the same lines of research, a study in Hong Kong reported that $89 \%$ of the healthcare workers who were in high risk situations exhibited psychological symptoms (14,15). Another cohort study carried out in the same region found that the rates of PTSD were higher among healthcare workers when compared to SARS-CoV survivors $(40.7 \%$ vs. $19 \%)$ (3). The cumulative incidence of mental disorders among survivors was $58.9 \%$, broken down as follows: depressive disorders $44 \%$, PTSD $47.8 \%$ at some point after the outbreak, panic disorder $13.3 \%$, agoraphobia $6.6 \%$, and social phobia $1.1 \%$ (3). Thirty months after the SARS$\mathrm{CoV}$ outbreak, the prevalence of mental disorders in the last month was $33.3 \%$, with PTSD being the most common diagnosis (25.6\%), followed by depressive disorders $(15.6 \%)$. Moreover, $61 \%$ of the SARS$\mathrm{CoV}$ survivors with a current diagnosis of PTSD also suffered from other psychiatric disorders (3).

\section{Post-traumatic stress disorder (PTSD)}

Depending on the social isolation characteristics, many events may become traumatic (5). A study conducted in 
Canada after the SARS-CoV identified psychological stress factors among healthcare workers, including a perception of being at risk of acquiring the infection, the impact of the outbreak on work life, a depressive mood, working in a high risk unit, caring for just one patient with SARS-CoV as opposed to many patients with the disease (6). Consistent with these findings, in healthcare workers followed during a three-year period in China, it was found that $10 \%$ experienced high levels of symptoms attributable to PTSD (16), and those who had been quarantined, those who had worked with SARS-CoV patients on their shifts, and those who had friends or relatives who had acquired the disease had a 2-3 fold probability of having PTSD symptoms, as compared to those who had not had those exposures (16). Moreover, they still had symptoms by 2006: close to $40 \%$ of the sample still had PTSD symptoms (16). A French study showed the impact on survivors of a pandemic outbreak in patients who required admission to the intensive care unit secondary to the $\mathrm{H}_{1} \mathrm{~N}_{1}$ infection, $40 \%$ of whom developed PTSD (17).

\section{Depression and anxiety}

In this current situation of worldwide confinement at home due to the COVID-19 outbreak, the vast majority of people are exposed to unprecedented stressful situations for an unknown period of time. This may not only increase the levels of stress, anxiety and depression during the day, but also disrupt sleep. It is important to highlight that, given the key role of sleep in regulating emotions, altered sleep patterns may have a direct impact on emotional performance the following day (18). Several factors may be associated with the normal response to stress in the form of depression and anxiety manifestations in patients quarantined due a pandemic. (5). A feeling of losing control is frequent in this context because, many times, individuals lack certainty about the end result or when the crisis will be over. That feeling of uncertainty, as well as restrictions derived from preventive social isolation, the possibility of all future plans changing dramatically, and sudden separation from the social or family context, are frequent catalysts of depression and anxiety (19). These clinical conditions, in social isolation circumstances, may occur as part of an adaptive disorder or an adjustment reaction which, in many cases, does not warrant pharmacological treatment (8). A $7 \%$ prevalence of MDD has been suggested following an outbreak (1). Other studies have shown that $10-35 \%$ of the SARS-CoV survivors exhibited symptoms suggestive of anxiety, depression, or both, during the early recovery phase $(2,3)$, while close to $44 \%$ of the survivors with some form of psychiatric disturbance had a depressive disorder (3). Proposed risk factors include: female gender, low socioeconomic level, inter-personal conflicts, frequent use of social media, low resilience, and lack of social support $\underline{(1,20)}$.

Regarding social stigma, during the SARS-CoV outbreak, close to $20 \%$ of healthcare-related population perceived discrimination from some of the people with whom they interacted (21). Specifically in Singapore, up to $49 \%$ of healthcare workers had similar perceptions when interacting with the general population (21).

Regarding willingness and ability to come to work during catastrophic events, a survey conducted among medical staff in New York (22) found that a higher proportion of practitioners would show up to work at the health service in circumstances such as a snow storm (80\%) or a natural disaster $(84 \%)$, and were less willing to go to work in circumstances associated with perceived personal risk, such as the SARS-CoV outbreak (48\%), a radiological hazard $(57 \%)$, or a chemical event $(68 \%)(22)$. It is worth noting that one of the measures that has enabled healthcare professionals to feel safer in their work places and which contributes to their sense of wellbeing is the availability of personal protection equipment (PPE). It was found that these people would be more willing to work during a catastrophic event if they had adequate PPE, given that the perception of personal risk or risk to their families is one of the factors which greatly influences the willingness to show up to work in those situations (22). Both during the SARS-CoV outbreak as well as during this current COVID-19 pandemic, one of the determinantes of the high rate of adjustment reactions and psychiatric illnesses is the nature of a new and highly contagious virus of unpredictable behavior which has required mandatory social isolation (9) and which, moreover, poses an impending threat to life and physical health (for the healthcare staff) and creates the fear of cross contamination of families and friends. Additionally, during clinical practice, physicians are faced with professional dilemmas due to the lack of resources and disproportionate number of clinical cases, increasing the level of stress (11).

\section{COVID-19 MENTAL HEALTH DISTURBANCES IN THE AFFECTED POPULATION}

In a pandemic, fear heightens stress and anxiety in healthy individuals and intensifies symptoms in people with preexisting mental disorders (23). Patients diagnosed with COVID-19 or suspected of having the infection may experience intense emotions and behavioral responses, apart from fear, boredom, loneliness, insomnia or rage (23). These conditions may evolve to disorders such as depression, panic attacks, PTSD, psychotic symptoms and suicide (19), which are especially prevalent among quarantined patients, in whom psychological stress is greater (24).

A study conducted among 1210 inhabitants in 194 cities in China, using the Impact of Event Scale-Revised and the Anxiety and Stress Scale, revealed that $53.8 \%$ of the participants had experienced moderate or severe psychological impact (7); $16.5 \%$ moderate-to-severe depressive symptoms; $28.8 \%$ moderate-to-severe anxiety; and $8.1 \%$ moderate-to-severe 
stress levels $(\underline{7)}$. The majority of respondents (84.7\%) spent 20-24 hours a day at home; $75.2 \%$ were worried that their relatives could acquire the COVID-19 infection, and $75.1 \%$ were satisfied with the amount of health information available (7).

Another study performed during the early days of the COVID-19 outbreak in 2020 reported a $34.0 \%$ prevalence of insomnia in frontline healthcare professionals (14), compared with a study in 1563 healthcare professionals that found that close to $36.1 \%$ had sleep disorders, more than half (50.7\%) reported depressive symptoms, and $44.7 \%$ reported anxiety symptoms $(25,26)$.

Using the 9-item Patient Health Questionnaire, another cross-sectional study carried out among 1257 healthcare workers in 34 hospitals caring for COVID-19 patients in China, found that, of the medical and nursing staff working in Wuhan, $34.4 \%$ had mild disorders (PHQ-9 average: 9.0) with $6.2 \%$ having severe disturbances (PHQ-9 average: 15.1) immediately after the epidemic (14). Moreover, $36.3 \%$ had looked into psychological content such as books on mental health, $50.4 \%$ had accessed psychological resources available in the media, such as on-line information on mental health and coping methods, and $17.5 \%$ had participated in counseling or psychotherapy sessions (14).

In terms of the consequences of a pandemic, there are two sides to the coin, particularly as relates to the consequences of social isolation. Although the vast majority of mental health repercussions have been reported in prior studies conducted during past epidemiological outbreaks and studies derived from this pandemic have been negative, it is also important to assess the positive impact of social isolation. A survey conducted among families in Hong Kong at the end of the SARS-CoV epidemic reported that $60 \%$ were more concerned with the feelings of their family members, two-thirds paid more attention to their mental health after the outbreak, and $35-40 \%$ devoted more time to rest and exercise $\underline{(27)}$.

\section{RECOMMENDATIONS}

The main short-term measures include the use of psychological first aid (PFA) (5), designed to foster a respectful support relationship between patients and therapists, assessment of critical needs and early intervention in an attempt at bringing stress or bereavement responses to an "expected normal level" (5). The aim of this intervention model is to provide immediate help and support to individuals living in anguish due to a recent crisis, and requires active listening without feeling the pressure to talk; it is not intrusive because it recognizes that people have the right to accept or reject the intervention (28). PFA is a crucial first step to ensure care, reassurance and support; it does not provide treatment for a mental health problem and it cannot be expected to be a long-term solution (29). The model also seeks to promote and support positive thinking about the future and educate in techniques to reduce stress and hyperresponsiveness levels, including deep or diaphragmatic breathing, progressive muscle relaxation and guided imagery (5). Early support must also be provided to the healthcare team to ensure adequate preparedness of the staff for facing work and its associated challenges, within the framework of a respectful and transparent relationship, without false guarantees or hopes, providing a comprehensive and accurate view of what they will have to face, with no euphemisms and in simple terms (11). This could be accomplished by means of discussions based on Schwarz rounds $\underline{(30)}$ and Balint groups (31). It is important to highlight that avoidance is a core symptom in trauma (11): the staff is "too busy" or repeatedly "unavailable" to attend these discussions. If it is associated with lower performance as a result of poor mental health, it will undoubtedly have a direct impact on the ability to operate and on the health of the team members. Therefore, leadership must make it their duty to be aware of the physical and mental health status of their people and communicate with them constantly in order to ensure early identification and support (11).
Measures that can be implemented long-term or after an outbreak include the use of trauma-centered therapies. Cognitive-behavioral therapy is designed to diminish or dismantle automatic negative, catastrophic and pessimistic thoughts about the future (5). Moreover, a support approach must be put in place, with psychotherapeutic interventions focused on recovering the sense of autonomy, emphasizing the acceptance of loss (5). Notable in this group is cognitive processing therapy (CPT) because it focuses on trauma and aims to resolve dysfunctional beliefs and attributions associated with the traumatic event; for example, beliefs associated with COVID-19 could be "if I leave my home, I will fall ill and die" or "I am completely helpless, there is nothing I can do". These are then confronted through the process of weighing the evidence, reviewing exceptions, and recognizing problem thought patterns such as "jumping to conclusions"(32). Another form of therapy that could be implemented is eye movement desensitization and reprocessing (EMDR) for PTSD. These therapies are complemented with psychopharmacological treatment, mainly based on the use of selective serotonin or noradrenaline re-uptake inhibitors (SSRI/ SNRI) during a period of 6 to 12 months to prevent relapses and symptom recurrences (5).

Measures that may help cope with the challenges inherent to the service must be designed to reflect and learn from difficult experiences in order to create a meaningful narrative instead of a traumatic one (11). This includes sharing the experience with a fellow worker, systematic and organized implementation of break schedules, and organization of events designed to provide verbal and other forms of recognition of the staff for their work (5).

It is important to translate scientific knowledge into timely pragmatic public health measures, as well as to prepare the community, in order to prevent and mitigate the neuropsychiatric sequelae of an outbreak. This is a critical step towards reducing long-term consequences and costs (Table 1) (5). Three main factors must be considered when developing 
mental health strategies: 1) setting up multidisciplinary mental health teams consisting of psychiatrists, psychiatric nurses, clinical psychologists and other mental health professionals; 2) ensuring clear communication at all times, with accurate and regular updates on the COVID-19 pandemic; and 3) setting up psychological counseling services through telemedicine (11,33-35). On the other hand, interventions should be centered on three key components: 1) understanding the mental health status in different populations affected by the COVID-19 outbreak; 2) identification of people at a high risk of suicide and aggression; 3) provision of adequate psychological interventions for those people who need them (26). Another useful recommendation is to prioritize or create a hierarchy of interventions, dividing the population according to a 4-level classification (26): Level 1 includes the most vulnerable individuals to mental health problems, i.e., hospitalized patients with confirmed infection or severe physical conditions, frontline healthcare professionals and administrative staff; Level 2 includes isolated patients with symptoms of infection, close contacts and patients admitted to clinical centers serving people affected by the outbreak; Level 3 includes individuals in close contact with people in levels 1 and 2, i.e., family members, colleagues, friends and volunteer first responders; Level 4 includes individuals involved in prevention and control of the epidemic, e.g., healthy individuals in social isolation (26).

Considering that confinement time during an outbreak may be used to create positive and healthier changes in lifestyle and to improve family relationships, mental health campaigns may be designed to focus on these areas in order to make sure that the changes can be maintained over time (27). At this time, the general population confined in their homes, but particularly healthcare, support, administrative and housekeeping staff who are in the frontlines in the battle against COVID-19, are experiencing great uncertainty. Additionally, healthcare workers have to face a greater work load with high exposure to the virus and to the hospital environment. This is compounded by the stigma associated with their condition as healthcare workers, the burden of family duties and the need to look out for emotional manifestations in their patients and family members. Consequently, the resilience of this population group is put to the test in the face of adversity. It is known that pandemics can trigger various cognitive, behavioral, affective and physical reactions among healthcare workers, creating the need for psychological and/ or psychiatric support. All this makes it necessary to ensure that healthcare workers look after their mental health and not hesitate to resort to the mental health services offered currently through telemedicine by most health insurance companies (Chart 1).

TABLE 1. Mental health recommendations during the COVID-19 pandemic.

Recommendation

Providing useful information $(5,36)$.

\section{Objective}

It is important for people to understand the data correctly in order to temper excess stress (e.g., anxiety, depression, etc.) due to inappropriate perceptions $\underline{(37)}$.

Working with public health officials to create communication that is appropriate for the culture of the population in order to mobilize preparedness without creating panic $(5,36)$.

To provide permanent information about the progress of the measures adopted in order to reduce stress and create awareness regarding public participation (37).

To ensure medical treatment provision. Setting up a medical service to treat the disease and informing the people about how to gain access is critical. That way, people will be able to receive help on time if they have the infection and improve their sense of control over the risks, in order to avoid an exaggerated perception of social risk (37).

To provide more leisure services in order to improve quality of life. People may be more willing to cooperate when their vital and leisure needs are met (things such as on-line shopping, entertainment, etc.) (37). 
CHART 1. Recommendations for coping with stress.

\section{Whenever possible, maintain your usual routines}

- Keep busy and focus on your daily activities.

- Make sure you allocate enough time to eat, exercise and rest.

- Avoid the use of psychoactive drugs and alcohol.

- Keep in touch with family and friends.

- Shy away from too much information about the pandemic.

- Pay attention to information on how to remain safe and healthy.

- Try to talk with someone about your feelings in case you are overcome by fear or worry.

\section{Think about the children}

- Discuss feelings together, with the family, and explain that it is normal to be worried when going through a stressful situation.

- Share information that they may understand.

- Let them know that, as a family, they will remain protected, and reassure them.

- Show them that you care, and hug them often.

- Maintain their routines with play and fun.

- Teach them self-care habits to ward off infectious diseases, such as hand washing.

SourcE: Authors, based on Elizarrarás-Rivas et al. (38)

\section{CONCLUSIONS}

Pandemics and the ensuing need for social isolation, have had a significant toll on mental health, during and after the outbreak, leading to long lasting pathological emotional responses that may result in highly disabling mental disorders, mainly PTSD and MDD, as well as anxiety disorders. This current COVID-19 pandemic will result in an increase in psychological disturbances in the general population but particularly among healthcare workers, creating a second mental health outbreak or epidemic. Therefore, it is crucial to implement strategies designed to anticipate that impact, setting priorities in based on the vulnerable or high risk populations identified. Early interventions include psychological first aid and multidisciplinary support teams, which may be reinforced later with traumafocused cognitive-behavioral therapies.

\section{Conflict of interest}

None declared by the authors.

\section{Funding}

None.

\section{Acknowledgements}

None.

\section{Authors' contributions}

J R-O, D C-Q, C L-C, F Y-C and F E-C. Help with the search, analysis of the referenced medical literature, and participation in the preparation of the manuscript.

\section{REFERENCES}

1. Torales ], O'Higgins M, Castaldelli-Maia JM, Ventriglio A. The outbreak of COVID-19 coronavirus and its impact on global mental health. Int ] Soc Psychiatry. 2020:20764020915212. DOI: $10.1177 / 0020764020915212$.

2. Wu KK, Chan SK, Ma TM. Posttraumatic stress after SARS. Emerg Infect Dis. 2005;11(8):1297300. DOI: 10.3201/eid1108.041083.

3. Mak IW, Chu CM, Pan PC, Yiu MG, Chan VL. Long-term psychiatric morbidities among SARS survivors. Gen Hosp Psychiatry. 2009;31(4):318-26. DOI: 10.1016/j.genhosppsych.2009.03.001.

4. Kim H-C, Yoo S-Y, Lee B-H, LeeSH, Shin H-S. Psychiatric findings in suspected and confirmed middle east respiratory syndrome patients quarantined in hospital: A Retrospective chart analysis. Psychiatry Investig. 2018;15(4):35560. DOI: 10.30773/pi.2017.10.25.1.

5. Huremovic D. Psychiatry of pandemics: A mental health response to infection outbreak. Switzerland: Springer International Publishing; 2019. DOI: 10.1007/978-3-030-15346-5.

6. Styra R, Hawryluck L, Robinson S, Kasapinovic $\mathrm{S}$, Fones C, Gold WL. Impact on health care workers employed in high-risk areas during the Toronto SARS outbreak. ] Psychosom Res. 2008;64(2):177-83. DOI: 10.1016/j.jpsychores.2007.07.015.

7. Wang C, Pan R, Wan X, Tan Y, Xu L, Ho CS, et al. Immediate psychological responses and associated factors during the initial stage of the 2019 coronavirus disease (COVID-19) epidemic among the general population in China. Int ] Environ Res Public Health. 2020;17(5). DOI: 10.3390/ijerph17051729.

8. Chen Q, Liang M, Li Y, Guo J, Fei D, Wang L, et al. Mental health care for medical staff in China during the COVID-19 outbreak. Lancet Psychiatry. 2020;7(4):e15-e6. DOI: 10.1016/S22150366(20)30078-X.

9. Chan AO, Huak CY. Psychological impact of the 2003 severe acute respiratory syndrome outbreak on health care workers in a medium size regional general hospital in Singapore. Occup Med (Lond). 2004;54(3):190-6. DOI: 10.1093/ occmed/kgho27. 
10. Greenberg N, Docherty M, Gnanapragasam $\mathrm{S}$, Wessely S. Managing mental health challenges faced by healthcare workers during covid-19 pandemic. BM]. 2020;368:m1211. DOI: 10.1136/bmj.m1211.

11. Xiang YT, Jin Y, Cheung T. Joint international collaboration to combat mental health challenges during the coronavirus disease 2019 pandemic. JAMA Psychiatry. 2020. DOI:10.1001/jamapsychiatry.2020.1057.

12. Peng EY, Lee MB, Tsai ST, Yang CC, Morisky $D E$, Tsai LT, et al. Population-based post-crisis psychological distress: an example from the SARS outbreak in Taiwan. J Formos Med AsSoc. 2010;109(7):524-32. DOI: 10.1016/SO9296646(10)60087-3.

13. Lee SM, Kang WS, Cho AR, Kim T, Park JK. Psychological impact of the 2015 MERS outbreak on hospital workers and quarantined hemodialysis patients. Compr Psychiatry. 2018;87:123-7. DOI: 10.1016/j.comppsych.2018.10.003.

14. Lai ], Ma S, Wang Y, Cai Z, Hu J, Wei N, et al. Factors associated with mental health outcomes among health care workers exposed to coronavirus disease 2019. JAMA Netw Open. 2020;3(3):e203976. DOI: 10.1001/jamanetworkopen.2020.3976.

15. Chua SE, Cheung V, Cheung C, McAlonan GM, Wong JWS, Cheung EPT, et al. Psychological effects of the sars outbreak in hong kong on high-risk health care workers. Can J Psychiatry. 2004;49(6):391-3. DOI: $10.1177 / 070674370404900609$.

16. Wu P, Fang Y, Guan Z, Fan B, Kong ], Yao Z, et al. The psychological impact of the SARS epidemic on hospital employees in China: exposure, risk perception, and altruistic acceptance of risk. Can ] Psychiatry. 2009;54(5):302-11. DOI: $10.1177 / 070674370905400504$.

17. Luyt CE, Combes A, Becquemin MH, Beigelman-Aubry $C$, Hatem S, Brun AL, et al. Long-term outcomes of pandemic 2009 influenza $A\left(\mathrm{H}_{1} \mathrm{~N}_{1}\right)$-associated severe ARDS. Chest. 2012;142(3):583-92. DOI: 10.1378/ chest.11-2196.

18. Altena E, Baglioni C, Espie CA, Ellis ], Gavriloff D, Holzinger B, et al. Dealing with sleep problems during home confinement due to the COVID-19 outbreak: practical recommendations from a task force of the European CBT-I Academy. J Sleep Res. 2020. DOI: 10.1111/ jsr.13052.
19. Xiang YT, Yang Y, Li W, Zhang L, Zhang Q, Cheung $\mathrm{T}$, et al. Timely mental health care for the 2019 novel coronavirus outbreak is urgently needed. Lancet Psychiatry. 2020;7(3):228-9. DOI: 10.1016/S2215-0366(20)30046-8.

20. Mowbray H. In Beijing, coronavirus 2019$\mathrm{nCoV}$ has created a siege mentality. BM]. 2020;368:m516. DOI: 10.1136/bmj.m516.

21. Park JS, Lee EH, Park NR, Choi YH. Mental health of nurses working at a government-designated hospital during a MERSCoV Outbreak: A Cross-sectional study. Arch Psychiatr Nurs. 2018;32(1):2-6. DOI: 10.1016/j. apnu.2017.09.006.

22. Qureshi K, Gershon RR, Sherman MF, Straub T, Gebbie E, McCollum M, et al. Health care workers' ability and willingness to report to duty during catastrophic disasters. J Urban Health. 2005;82(3):378-88. DOI: 10.1093/jurban/jtio86.

23. Shigemura ], Ursano R], Morganstein JC, Kurosawa M, Benedek DM. Public responses to the novel 2019 coronavirus (2019-nCoV) in Japan: Mental health consequences and target populations. Psychiatry Clin Neurosci. 2020;74(4):281-2. DOI: 10.1111/pcn.12988.

24. Brooks SK, Webster RK, Smith LE, Woodland L, Wessely S, Greenberg N, et al. The psychological impact of quarantine and how to reduce it: rapid review of the evidence. The Lancet. 2020;395(10227):912-20. DOI: https://doi. org/10.1016/S0140-6736(20)30460-8.

25. Y Zhang C, Yang L, Liu S, Ma S, Wang Y, Cai $Z$, et al. Survey of insomnia and related social psychological factors among medical staff involved in the 2019 novel coronavirus disease outbreak. Front Psychiatry. 2020;11. DOI: 10.3389/fpsyt.2020.00306.

26. Li W, Yang Y, Liu ZH, Zhao Y], Zhang Q, Zhang $L$, et al. Progression of mental health services during the COVID-19 outbreak in China. Int ] Biol Sci. 2020;16(10):1732-8. DOI: 10.7150/ ijbs. 45120 .

27. Lau JT, Yang X, Tsui HY, Pang E, Wing YK. Positive mental health-related impacts of the SARS epidemic on the general public in Hong Kong and their associations with other negative impacts. J Infect. 2006;53(2):114-24. DOI:10.1016/j.jinf.2005.10.019.

28. Minihan E, Gavin B, Kelly BD, McNicholas F. Covid-19, mental health and psychological first aid. Irish ] Psychol Med. 2020;1-12. DOI:10.1017/ipm.2020.41.
29. Fox JH, Burkle FM, Bass J, Pia FA, Epstein JL, Markenson D. The effectiveness of psychological first aid as a disaster intervention tool: Research analysis of peer-reviewed literature from 1990-2010. Disaster Med Public Health Prepar. 2012; 6(03), 247-52. DOI: 10.1001/ dmp.2012.39.

30. Flanagan E, Chadwick R, Goodrich ], Ford C, Wickens R. Reflection for all healthcare staff: A national evaluation of Schwartz Rounds. ] Interprof Care. 2020;34(1):140-2. DOI: 10.1080/13561820.2019.1636008.

31. Roberts M. Balint groups: a tool for personal and professional resilience. Can Fam Physician. 2012;58(3):245-7.

32. Moring JC, Dondanville KA, Fina BA, Hassija C, Chard K, Monson, et al. Cognitive processing therapy for posttraumatic stress disorder via telehealth: Practical considerations during the COVID-19 pandemic. J Traum Stress. 2020. DOI:10.1002/jts.22544.

33. Ornell F, Schuch JB, Sordi AO, Kessler FHP. "Pandemic fear" and COVID-19: mental health burden and strategies. Braz ] Psychiatry. 2020. DOI:10.1590/1516-4446-2020-0008.

34. Ohannessian R, Duong TA, Odone A. Clobal telemedicine implementation and integration within health systems to fight the COVID-19 pandemic: A call to action. JMIR Public Health Surveill. 2020;6(2):e18810. DOI: 10.2196/18810.

35. Moazzami B, Razavi-Khorasani N, Dooghaie Moghadam A, Farokhi E, Rezaei N. COVID-19 and telemedicine: Immediate action required for maintaining healthcare providers weIl-being. J Clin Virol. 2020;126:104345. DOI: 10.1016/j.jcv.2020.104345.

36. Manderscheid RW. Preparing for pandemic Avian influenza: ensuring mental health services and mitigating panic. Arch Psychiatr Nurs. 2007;21(1):64-7. DOI: 10.1016/j. apnu.2006.10.003.

37. Li S, Wang Y, Xue ], Zhao N, Zhu T. The Impact of COVID-19 epidemic declaration on psychological consequences: A study on active Weibo users. Int ] Environ Res Public Health. 2020;17(6). DOI: 10.3390/ijerph17062032.

38. Elizarrarás-Rivas ], Vargas-Mendoza JE, Mayoral-García M, Matadamas-Zárate C, Elizarraras-Cruz A, Taylor M, et al. Psychological response of family members of patients hospitalised for influenza $\mathrm{A} / \mathrm{H}_{1} \mathrm{~N} 1$ in Oaxaca, Mexico. BMC Psychiatry. 2010;10:104. DOI: 10.1186/1471-244X-10-104. 